pregnancy. It would, however, be most inappropriate in the context of a sudden increase in blood pressure in the third trimester, particularly if the patient was pregnant for the first time. The reason for this does not lie in the inherent danger of this modest elevation in the blood pressure but the warning it gives of possible impending severe pre-eclampsia. The possibility that this dangerous condition may develop very rapidly justifies a policy of admission in predisposed patients. The alternative policy of outpatient management is only permissible in the case of very reliable patients who have been taught to use Albustix daily.

It is stated that diuretics "do not improve the prognosis of hypertension in pregnancy." While this is certainly true, it should be remembered that treatment with methyldopa itself has little or no influence on fetal prognosis. ${ }^{1}$ The most important reason for withholding diuretic treatment in pre-eclampsia is that it may aggravate the hypovolaemia which is characteristic of this condition. ${ }^{2}$

The first agent mentioned for the parenteral treatment of acutely raised blood pressure is diazoxide. While small doses of this substance have been used without ill effect, the first line of treatment in most hospitals is parenteral hydral lazine. ${ }^{3}$ Inadequate response to this well-tried agent is extremely rare and, furthermore, it does not have the antidiuretic and tocolytic effects of diazoxide. Infusions of labetolol were recommended and I have found this agent to be safe and effective in lowering acute elevations of blood pressure in pregnancy. The literature contains no reference to its use in obstetrics, though this may well become the drug of first choice in fulminating pre-eclampsia, as it combines considerable potency with more gradual hypotensive effect. This is less likely to jeopardise uteroplacental blood flow.

I agree with the authors' statement that longterm use of beta-blockers in pregnancy is controversial. ${ }^{4}$ However, many authors have failed to confirm reports of an increased perinatal mortality and one author has found an improvement in fetal outcome when oxprenolol was used for hypertension in pregnancy. ${ }^{5}$

The importance of monitoring renal output in fulminating cases is mentioned but another important aspect of therapy is the prevention of eclampsia by means of adequate sedation. Intravenous diazepam and chlormethiazole or intramuscular magnesium sulphate may be used for this purpose.

R J LILFORD

Department of Reproductive Physiology,
St Bartholomew's Hospital Medical College,

London EC1

Redman CWG, Beilin LJ, Bonnar J, Ounsted MK. Lancet 1976;ii:753-6.

2 Lawson J. Clin Obstet Gynaecol 1977;4:707-15.

3 Redman CWG. Clin Obstet Gynaecol 1977;4:685-705. Lieberman BA, et al. Br f Obstet Gynaecol 1978; 85:678-83.

Gallery EDM, Saunders DM, Hungar SM, Györy AZ. Br Med f 1979;1:1591-4

SIR,-The management of hypertension in general practice remains a real problem, and I find myself increasingly confused. In an article in the $B M \mathcal{F}$ on hypertension in the elderly (25 October, p 1122) I am advised that the threshold above which treatment should be considered is higher in older patients, and I am told blood pressures of 200/100 mm Hg may probably be left untreated in 70-year-olds, but above this level the doctor might consider drug treatment (my italics). Pretty vague advice.

I then turned to the Prescribers' Fournal, a much-respected and widely read publication sent to all general practitioners in the NHS. Here, on page 119 of the October issue, I am told, "If treatment was started for uncomplicated mild hypertension (a diastolic pressure less than $105 \mathrm{~mm} \mathrm{Hg}$ ) or for uncomplicated hypertension in an elderly patient unsuccessfully drug therapy may be discontinued as there is at present little evidence that such patients benefit from treatment" (again my italics).

If this is indeed current medical teaching, surely the advice should be that treatment must be discontinued (as it apparently serves no useful purpose), and should logically never have been started in the first place. How much time and money are we wasting prescribing unnecessarily, for a condition which in many is a natural concomitant of the aging process and how much harm are the drugs we are giving actually doing ?

High Wycombe, Herts HP14 3TG

TONy Keable-Elliot

${ }^{1}$ Ramsay LE. Prescribers' fournal 1980;20:115-21.

SIR, - The statement in the article dealing with blood pressure reduction in the elderly (25 October, p 1120) by Dr Liam T Bannan and others that there are no published trials of blood pressure reduction in patients over 65 is probably not true. In the often-quoted Framingham study, strong evidence was found that the risk from cardiovascular disease was twice as high for persons aged $65-74$ of both sexes with systolic blood pressures of $160 \mathrm{~mm}$ $\mathrm{Hg}$ and over as for those with systolic blood pressures of $130 \mathrm{~mm} \mathrm{Hg}$ and less. ${ }^{1}$ Similarly the Veterans Administration study ${ }^{2}$ found a high incidence of stroke, congestive heart failure, and coronary artery disease in men aged 60 and over with diastolic blood pressure of 90-114 $\mathrm{mm} \mathrm{Hg}$.

Since lowering of blood pressure in the elderly may result in reduced cerebral perfusion and may cause dizzy turns, lightheadedness, falls, and even transient ischaemic attacks and strokes, Graham ${ }^{3}$ and Jackson et al did not support the idea of treating the elderly hypertensives. Dall, speaking at a recent symposium on hypertension in the elderly at the Royal College of Physicians, concluded that an elevated systolic but not diastolic blood pressure was a major cause of morbidity and mortality in the elderly. So, though the issue is unsettled, published material does exist.

London Hospital (Mile End),

K L GUPtA

${ }^{1}$ Kannel WB. Br Med f 1976;i:1255.

Veterans Administrative Cooperative Study Group on Antihypertensive Agents. Circulation 1972;45

3 Graham DI. Br Med 71975 ;iv: 739.
${ }^{4}$ Jackson G, Peirscianowski TA, Mahon W, London J. Lancet 1976;ii:1317-8.

SIR, - There have been a number of disturbing reports of patients who have suffered infarction of important organs such as the heart, brain, or bowel following excessively rapid reduction of the blood pressure in malignant hypertension, as discussed in the series "ABC of blood pressure reduction" on 25 October (p 1120).

In order to minimise this risk $I$ have for many years made it a rule that blood pressure must be measured immediately before each individual dose of hypotensive agent is given during the early weeks of treatment. Since the systolic pressure is generally measured more reliably than the diastolic by nursing staff in training, the instruction on the Aberdeen treatment sheet carries the sentence: "Give only if the diastolic pressure exceeds $\mathrm{mm}$ of $\mathrm{Hg}$." The exact figure is determined by an experienced doctor at one-to-three-day intervals and it will depend on the clinical situation.

Royal Liverpool Hospital,

H J Goldsmith

Liverpool L7 8XP

SIR,-May we make two comments on "ABC of blood pressure reduction-the size of the problem" by Dr Liam Bannan and others (4 October, p 921)?

Reference to diastolic pressures at which to initiate treatment should define the phase which is being used, 4 or 5 . As there may be so much as $10 \mathrm{~mm} \mathrm{Hg}$ difference between the two, ${ }^{1}$ the recommendation to treat pressures of "consistently $100 \mathrm{mg} \mathrm{Hg}$ or more" will bring a sizable number of patients into treatment if muffling is used as a criterion who would be excluded on the basis of extinction of sound.

Under "Drugs inducing hypertension" the authors mention oral contraceptives and oestrogen therapy. Whereas oral contraception of the oestrogen-progestogen type may elevate blood pressure, sometimes dangerously, we would be interested in any evidence the authors have that oestrogen therapy, in the dosage in which it is usually given for menopausal problems, has such an effect.

JEAN CoOpe

JOHN COOPE

Bollington,
Nr Macclesfield SK10 5JL

${ }^{1}$ D'Souza MF, Irwig LM. Br Med f 1976;iv:814.

\section{Protection against pertussis by} immunisation

SIR,-We studied 622 cases of whooping cough admitted to all infectious diseases and paediatric units in Glasgow between 1969 and $1980,{ }^{12}$ and were therefore interested in the article by $\mathrm{Dr} M$ W McKendrick and others (22 November, p 1390) describing recent experience of the disease in Birmingham.

Although we chose slightly stricter criteria for inclusion, there are some interesting comparisons. The overall uptake of complete courses of pertussis vaccine in Glasgow fell from $71 \%$ in 1973 to $45 \%$ in 1978 , which is still double that for Birmingham $(22 \%)$. The age distribution of children admitted to hospital was similar, but $19 \%$ of the Glasgow children over 6 months of age (10-year period) had been partially or fully immunised against pertussis compared with $4 \%$ in Birmingham (15-month period). While suggesting that the vaccine gives protection, albeit not complete, it may be that hospital admissions come from families where immunisation levels are atypical. We therefore compared a group of children admitted to hospital with measles over the same period. Nineteen per cent of the whooping cough cases had received at least one dose of pertussis vaccine compared with $72^{\circ}$ of those with measles-a highly significant difference.

Regarding complications, I was surprised at the low incidence of cyanotic attacks in the Birmingham study $(13 \%)$. In Glasgow they were so frequent $(85 \%)$ that we did not consider them to be complications. Prolonged apnoeic attacks occurred in 5\%, all under 4 years of age, and convulsions in $3 \%$, mostly in the 1-4 years age group, which is similar to 
the Birmingham findings. The overall pneumonia rate in Birmingham was higher $(40 \%)$ than in Glasgow $\left(26^{\circ}\right.$ ), where pneumonia was taken to mean either consolidation on chest radiograph or a chest infection which in the judgment of the attending physician required antibiotics. It would be interesting to know what "confirmation" by chest radiography means in the Birmingham study, since the difference may be explained by differing definitions.

We have been reluctant to draw definite conclusions from the complication rate in those children immunised against pertussis compared with those not immunised, since the numbers are small, and this may also apply to the Birmingham study. However, overall findings are similar, confirming that whooping cough still causes substantial numbers of hospital admissions for a prolonged and unpleasant illness and that immunisation appears to protect children from being admitted to hospital with the disease, either by preventing it altogether or by preventing serious complications.

University Department of

Infectious Diseases,

Ruchill Hospital,

' Walker E. Communicable Diseases (Scotland) Weekly Bulletin $1979 ; 46$ :vii

IW, Love WC, Chaudhuri AKR Datta JB. Journal of Infection (in press).

\section{Is coeliac disease underdiagnosed?}

SIR,-Not only is coeliac disease underdiagnosed, as suggested by Drs Christine $M$ Swinson and A J Levi (8 November, p 1258), but there is no accurate knowledge of its prevalence throughout the United Kingdom. Facts on the numbers, age distribution, etc, of coeliacs are essential not only to establish long-term medical complications (for example, lymphoma) but also to identify changes in the incidence, as a basis for recognising environmental factors which lead to the expression of the disease in genetically predisposed individuals. Moreover, as the treatment is life long there are financial and sociological implications for the patient and the National Health Service. With the support of the Scottish Home and Health Department and with the co-operation of all the physicians, paediatricians, and pathologists in the hospitals of Lothian Region, a project to establish a register of all coeliac patients in Lothian Region has been initiated. ${ }^{1}$ As yet the data are incomplete, but it is likely that the prevalence will exceed 1 in 1100.

A search of pathology department records for jejunal biopsies typical of coeliac disease has been used as one of the ways of identifying patients. As part of the project jejunal biopsies from all supposed coeliacs are being reviewed by three of the pathologists in the region. This has been completed for the Western General Hospital and our positive biopsy rates for recent years are very comparable with the Northwick Park experience (see table below)

The gastrointestinal unit has been established at this hospital since 1949 and currently some 1000 new outpatients with gastrointestinal disease are seen each year. Until 1975 jejunal biopsy was done on an inpatient basis. Since 1976 we have used a day-bed area (as described by Rainey and Buckley ${ }^{1}$ ) the procedure being performed by gastrointestinal investigation nurses. This has greatly facilitated the investigation of patients with malabsorption or diarrhoeal disease. It is most unusual for patients suspected of coeliac disease to be admitted, and we rarely perform investigations such as tests for faecal fats in such cases. The use of the day-bed area also makes it easie to arrange the repeat biopsies necessary for. the confirmation of diagnosis by gluten exclusion and challenge.

In view of the similar "positive biopsy rates" we attempted to compare our diagnosis rate in relation to new patients with that at Northwick Park Hospital. The Lothian Health Board publishes separate figures for new general medical outpatients and for new referrals to gastrointestinal, haematological, and other specialist outpatient clinics. In the Western General Hospital we felt that a combination of new general medical outpatients and new gastrointestinal and new haematological patients would be comparable to the Northwick Park category. Over the threeyear period 1976-1978 this gave a mean diagnosis rate in new outpatients of 1 in 209.

We do not feel that it is reasonable to place too much significance on this result because the known specialist interest in any hospital will influence the pattern of referral. The membership of the Coeliac Society fails to provide an accurate indication of the prevalence of the disease in Scotland. We estimate that there are around 650 living coeliacs in the Lothians and current membership of the local branch is around 150. Recent and future recruitment to the society may however reflect an increasing awareness of this underdiagnosed condition.

EDITH A RIFKIND

A Busuttil

University Gastrointestinal Unit,

ANNE FERGUSON

Western General Hospital

' Logan RFA, Rifkind EA, Ferguson A. In: McConnell $\mathrm{RB}$, ed. The genetics of coeliac disease. Lancaster:

2 Rainey JB, Ruckley CV. Br Med J 1979; ii :714-7.
Results of biopsies in relation to coeliac disease at Western General Hospital, Edinburgh

\begin{tabular}{|c|c|c|c|c|c|c|c|}
\hline & & 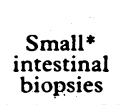 & $\begin{array}{l}\text { Number } \\
\text { diagnostic } \\
\text { of coeliac } \\
\text { diseaset }\end{array}$ & $\begin{array}{c}\text { Positive } \\
\text { diagnostic } \\
\text { biopsy } \\
\text { rate }\end{array}$ & $\begin{array}{l}\text { Number diagnostic of } \\
\text { coeliac disease } \\
+ \text { severe villous atrophy } \\
+ \text { partial villous atrophy }\end{array}$ & $\begin{array}{c}\text { Abnormal } \\
\text { biopsy } \\
\text { rate }\end{array}$ & $\begin{array}{l}\text { New } \\
\text { cases }\end{array}$ \\
\hline $\begin{array}{l}1962 \\
1963\end{array}$ & $\begin{array}{l}\because \\
\because\end{array}$ & $\begin{array}{l}45 \\
89 \\
\end{array}$ & $\begin{array}{l}4 \\
7\end{array}$ & $\begin{array}{l}1: 11 \cdot 3 \\
1: 12 \cdot 7\end{array}$ & $\begin{array}{r}8 \\
10\end{array}$ & $\begin{array}{l}1: 7 \cdot 5 \\
1: 8 \cdot 9\end{array}$ & $\begin{array}{l}3 \\
5\end{array}$ \\
\hline $\begin{array}{l}1967 \\
1968 \\
\end{array}$ & $\because$ & $\begin{array}{r}72 \\
114 \\
\end{array}$ & $\begin{array}{r}8 \\
14 \\
\end{array}$ & $\begin{array}{l}1: 9 \\
1: 8 \cdot 1\end{array}$ & $\begin{array}{l}14 \\
24\end{array}$ & $\begin{array}{l}1: 5 \cdot 1 \\
1: 4 \cdot 6\end{array}$ & $\begin{array}{r}3 \\
10\end{array}$ \\
\hline $\begin{array}{l}1972 \\
1973\end{array}$ & .. & $\begin{array}{r}95 \\
107\end{array}$ & $\begin{array}{r}9 \\
18\end{array}$ & $\begin{array}{l}1: 10 \cdot 6 \\
1: 5.9\end{array}$ & $\begin{array}{l}28 \\
28\end{array}$ & $\begin{array}{l}1: 3.3 \\
1: 3.8\end{array}$ & $\begin{array}{l}11 \\
15\end{array}$ \\
\hline $\begin{array}{l}1977 \\
1978\end{array}$ & $\therefore$ & $\begin{array}{l}231 \\
231\end{array}$ & $\begin{array}{l}30 \\
29\end{array}$ & $\begin{array}{l}1: 7 \cdot 7 \\
1: 7.9\end{array}$ & $\begin{array}{l}70 \\
67\end{array}$ & $\begin{array}{l}1: 3 \cdot 3 \\
1: 3 \cdot 4\end{array}$ & $\begin{array}{l}19 \\
18\end{array}$ \\
\hline
\end{tabular}

*Biopsies carried out for inflammatory, neoplastic, and ulcerative small intestinal conditions are excluded. Biopsie include adult and paediatric cases from the North Lothian District of Lothian Health Board. +Will comprise biopsies from all new cases; also variable proportion of follow-up biopsies in treated and untreated
patients.

\section{Prevention of mumps}

SIR,-Your leading article (8 November, p 1231) voices reservations about mumps vaccination that were weighed before the vaccine was introduced. It states the overwhelmingly positive American experience, which did not verify these reservations after 40 million doses and 13 years of routine immunisation. Yet it ignores this experience when it comes to outlining policy for a European country.

It should not be inferred that an upward trend in age distribution of mumps following vaccination is associated with higher incidence in older age groups. In the American sample quoted in the leading article, ${ }^{1}$ the slight upward trend in 1972-6 compared with 1967-71 was in fact associated with reduction of incidence at all ages, and by $55 \%$ in those over 15 years old. An upward trend in age distribution almost necessarily develops when a new vaccine is introduced well before the age of peak incidence of a disease, and it could be seen even when vaccination would not affect circulation of the agent. Confusion between these distinct indices, proportion of all cases contributed by an age group and incidence at that age, also plagues the discussion about measles vaccination. ${ }^{2}$

Increased incidence at higher age could be predicted if protection wanes years after vaccination, and a most reassuring aspect of the American experience is that protection and antibodies ${ }^{3}$ did not wane. Under certain conditions childhood vaccination that gives permanent protection could result in higher incidence after puberty. It would be due to delayed exposure of non-immune individuals who did not take the vaccine or in whom the vaccine did not take, and it would probably be a temporary phenomenon preceding the expected decrease. Apparently, these conditions are not easily realised, since such an increase over prevaccination levels has not been observed in the large American experience with mumps and measles vaccines (the opposite was seen), and there is no real proof of it in other developed countries. If this trend developed in any country, public health authorities could readily reverse it by improved vaccination.

The argument that mumps is generally mild is offset by the number of cases. Hard epidemiological evidence is difficult to gather, but sources concur that at least one person out of two will be ill in his lifetime owing to mumps virus, and many more can infect others. The illness load due to mumps and its many complications, benign as they usually but not always are, is therefore considerable. The economic justification for mumps vaccination is evident if, for example, one weighs school absenteeism and its related cost, the hospitalisation rate of about $1 \%$ in European countries, 5 and total cost of mumps after puberty.

The slow pace at which European countries recommend general mumps vaccination probably owes more to the fear that adding another vaccine to the package might have an adverse affect on the acceptance of other vaccines than to reservations about community effects of mumps vaccination. There is, however, little reason for this fear. Mumps vaccine is among the least "reactogenic" of all vaccines, and it can be associated inconspicuously with other vaccinations. It is not contested that mumps vaccination is a boon for the individual, and only beneficial effects on the community 